Pesq. Vet. Bras. 30(10):868-876, outubro 2010

\title{
Participação da excreção renal de cálcio, fósforo, sódio e potássio na homeostase em cães sadios e cães com doença renal crônica ${ }^{1}$
}

\author{
Pedro P. Martínez ${ }^{2 \star}$ e Marileda B. Carvalho³
}

\begin{abstract}
Martínez P.P. \& Carvalho M.B. 2010. [Participation of renal excretion of calcium, phosphorus, sodium and potassium on the homeostasis in healthy dogs and in dogs with chronic kidney disease.] Participação da excreção renal de cálcio, fósforo, sódio e potássio na homeostase em cães sadios e cães com doença renal crônica. Pesquisa Veterinária Brasileira 30(10):868-876. Departamento de Medicina Veterinária, Área de Clínica Médica de Pequenos Animais, Faculdade de Ciências Agrárias e Veterinárias, Universidade Estadual Paulista, Jaboticabal, SP 14870-000, Brazil. E-mail: pedromartinezpadua@ hotmail.com

In chronic kidney disease (CKD), the first problem to be solved by the organism is to maintain water and sodium homeostasis and, with the worsening of the renal injuries, other severe problems related to the calcium and phosphorus homeostasis emerge. The present study has the purpose to evaluate the renal excretion and serum profile of calcium, phosphorus, sodium and potassium in healthy dogs and in dogs with naturally acquired CKD. Three groups of adult male and female dogs of varied breeds were evaluated. Normal dogs were in the control group (G1) and the CKD dogs were distributed into two groups in accordance with the stage of renal function impairment (G2 e G3, respectively, stages 1-2 and stages 3-4, proposed by IRIS 2006 staging CKD). The G3 dogs showed increased serum levels of ionized calcium and phosphorus, in addition to the reduction of sodium levels. Regarding the renal excretion of the analyzed electrolytes, the G1 and G2 groups showed a decrease of filtered load and increase of fractional excretion, yet there were no significant variations on the urinary excretions. The results suggest that the kidneys of the CKD dogs can maintain similar values of electrolytes urinary excretion as the kidneys of normal dogs. The mechanism involves an increase of fractional excretion while glomerular filtration decreases. This compensation process, however, can lose its efficiency in the later stages of the disease, in relation to the maintenance of phosphorus and sodium serum levels.
\end{abstract}

INDEX TERMS: Renal disease, electrolytes, diseases of dogs, fractional excretion.

RESUMO.- Na doença renal crônica (DRC) a manutenção da homeostase de água e sódio é o primeiro problema a ser contornado pelo organismo e com o agravamento das lesões renais surgem outros problemas graves relacionados à homeostase de cálcio e fósforo. O presente estudo tem por escopo avaliar a excreção renal de cálcio, fósforo, sódio e potássio, e o perfil sérico destes eletrólitos em

\footnotetext{
${ }^{1}$ Recebido em 21 de dezembro de 2009.

Aceito para publicação em 14 de junho de 2010.

2 Pos-Graduando do Programa de Medicina Veterinária, Área de Clínica Médica, Faculdade de Ciências Agrárias e Veterinárias Universidade Estadual Paulista (Unesp), Jaboticabal, SP 14870-000, Brasil. *Autor para correspondência: pedromartinezpadua@ @otmail.com

${ }^{3}$ Departamento de Clínica e Cirurgia Veterinária Faculdade de Ciências Agrárias e Veterinárias Universidade Estadual Paulista (Unesp), Jaboticabal, SP 14870-000, Brasil.
}

cães normais e em cães com DRC naturalmente adquirida. Foram avaliados três grupos de cães adultos, machos ou fêmeas, de raças variadas. Animais normais compuseram o grupo controle (G1) e os cães com DRC foram distribuídos em dois grupos de acordo com os estágios de comprometimento da função renal (G2 e G3, respectivamente, estágios 1-2 e estágios 3-4, descritos pela IRIS 2006 staging CKD). Os cães do G3 apresentaram aumento das concentrações séricas de cálcio ionizado e fósforo, além de diminuição da concentração sérica de sódio. Quanto à excreção renal dos eletrólitos analisados, os animais dos grupos G1 e G2 apresentaram diminuição de carga filtrada e aumento de excreção fracionada, mas as excreções urinárias não variaram significativamente. Os resultados são indicativos de que os rins de cães com DRC podem manter a excreção urinária dos eletrólitos em valores se- 
melhantes aos dos normais. O mecanismo envolve aumento da excreção fracionada na medida em que haja diminuição da filtração glomerular. Esse processo de compensação, entretanto, pode perder a eficiência nos estágios mais avançados da enfermidade no que se refere à manutenção das concentrações séricas de fósforo e sódio.

TERMOS DE INDEXAÇÃO: Doença renal, eletrólitos, doenças de cães, excreção fracionada.

\section{INTRODUÇÃO}

A doença renal crônica (DRC) é caracterizada por sua natureza irreversível e, frequentemente, progressiva. Independentemente do tipo de lesão inicial, com o passar do tempo, são comprometidos glomérulos, túbulos e interstício culminando com perda de néfrons e diminuição da taxa de filtração glomerular (TFG). A reserva funcional dos rins e seus mecanismos compensatórios podem prevenir as faIhas funcionais por um período de tempo variável. Quando já esgotadas as possibilidades de adaptação e as alterações morfológicas atingem um ponto crítico, tem início o déficit funcional, caracterizado principalmente por diminuição da capacidade de concentrar a urina, manifestada por poliúria, e dificuldade para manter a homeostase de água e eletrólitos; quando restam menos que $25 \%$ deles, o paciente entra no quadro clínico denominado uremia, dentre as alterações que caracterizam a uremia, são de grande relevância o desequilíbrio hidroeletrolítico e o hiperparatireoidismo secundário renal que, por sua vez, têm consequências dramáticas (Finco 1995, Polzin \& Osborne 1995, Brown et al 1997, Rubin 1997).

Nos rins, o movimento de água está relacionado, de várias maneiras, ao transporte de sódio. A reabsorção de sódio no túbulo proximal se produz de modo isosmótico e está regulada para manter o volume sanguíneo, enquanto que na porção espessa ascendente da alça de Henle, a reabsorção do sódio sem água constitui a base tanto para a excreção do excesso de água, como para a conservação da água mediante produção de urina diluída ou concentrada (Gleadhill \& Mitchell 1999).

Pelo menos $98 \%$ do potássio encontrado no organismo estão dentro das células e estas têm um papel relevante nos mecanismos de regulação do íon. Entretanto, o balanço depende dos rins. O potássio é filtrado pelo glomérulo e parcialmente reabsorvido no túbulo proximal juntamente com outros eletrólitos que participam da reabsorção isosmótica de líquido e parte deste pode ser secretado no túbulo distal (Rosa et al. 1992, Berliner \& Gliebish 1998).

O cálcio presente no sangue encontra-se ligado a proteínas plasmáticas (principalmente albumina), formando complexos com pequenos ânions ou sob a forma ionizada livre. Só o componente ionizado é fisiologicamente ativo, e está regulado pelo paratormônio (Favus \& Langman 1986, Barber \& Elliot 1999). O cálcio não ligado a proteínas é filtrado pelos glomérulos e amplamente reabsorvido pelos túbulos. Em animais sadios isso resulta na recuperação de mais de $90 \%$ do cálcio filtrado (Rosol \& Capen 1996). O cálcio ionizado (Cai) exerce diferentes funções no organismo (Rosol et al. 1995). De um modo geral, a concentração sérica de cálcio total (SCat) reflete a concentração de Cai, contudo, no paciente com insuficiência renal crônica (IRC), esta relação se perde (Chew \& Nagode 1990).

O fósforo é o sexto elemento mais abundante no organismo e, dentre suas inúmeras funções, pode ser destacado o fornecimento de energia para as atividades celulares. Para tanto, o fosfato orgânico ocorre sob a forma de compostos de alta energia tais como creatina fosfato e o ATP. Cerca $85 \%$ do fosfato estão contidos nos ossos sob forma de hidroxiapatita, $14 \%$ estão nas células de tecidos moles como constituintes de compostos orgânicos e 1\% está presente no líquido extracelular. Do total de fosfatos no sangue, $30 \%$ apresentam-se sob forma orgânica como constituintes moleculares das hemácias e $70 \%$ são íons plasmáticos livres sob formas denominadas fosfato inorgânico (Pi) (Berndt \& Knox 1992, Knochel 1992). A excreção deste diminui com a redução da TFG e gera alterações no balanço de cálcio e fósforo (Knochel 1992).

A maioria dos casos de DRC tem curso insidioso e o diagnóstico costuma ser tardio, geralmente quando já existe déficit funcional. A manutenção da homeostase de água e sódio é o primeiro problema a ser contornado pelo organismo no estágio inicial da DRC, com o agravamento das lesões renais surgem outros problemas graves relacionados à homeostase de cálcio e fósforo. A caracterização da função renal nos processos de excreção de sódio, potássio, cálcio e fósforo, de acordo com o estágio da DRC, pode trazer fundamentação para intervenções terapêuticas mais efetivas. O presente estudo pretendeu avaliar a excreção renal de cálcio, fósforo, sódio e potássio, e o perfil sérico destes eletrólitos em cães normais e em cães com DRC naturalmente adquirida.

\section{MATERIAL E MÉTODOS}

\section{Grupos experimentais e laboratórios}

Foram avaliados 31 cães adultos, de diversas raças ou sem raça definida. Dezoito animais eram provenientes do canil mantido pelo Grupo de pesquisa em nefrologia e urologia veterinária (GPNUV) e os outros 13 eram pacientes em condição clínica estável, atendidos pelo Serviço de Nefrologia e Urologia veterinária da Universidade Estadual Paulista campus Jaboticabal. Para determinar a condição de sadio ou de doente renal crônico, todos os cães foram avaliados previamente (histórico, exame físico e exames complementares - patologia clínica e ultra-sonografia).

Treze cães sadios (8 machos e 5 fêmeas) compuseram o grupo controle (G1) e os demais compuseram os grupos de doentes renais crônicos. Para classificação dos animais com doença renal crônica (DRC) foram seguidos os critérios adotados pela International Renal Interest Society (IRIS, 2006) ${ }^{4}$.

Cinco animais (2 machos e 3 fêmeas) com DRC em estágio 1 ou 2 compuseram o G2 (DRC E1-2) e 13 animais (6 machos e 7 fêmeas) com DRC em estágio 3 ou 4 compuseram o G3 (DRC E3-4). No Quadro 1 estão sumariados os dados

\footnotetext{
${ }^{4}$ http:www.iris.kidney.com/guidelines/em/staging_ckd.shtml
} 
Quadro 1. Caracterização dos grupos de animais estudados, de acordo com a condição clínica (sadio ou doente renal crônico) e com a gravidade do comprometimento renal (cães sadios = controle; cães com doença renal crônica em estágio 1 ou 2 = DRC E1-2; cães com doença renal crônica em estágio 3 ou $4=$ DRC E3-4). Jaboticabal, 2008

\begin{tabular}{|c|c|c|c|}
\hline Parâmetros & $\begin{array}{l}\text { Cães } \\
\text { sadios }\end{array}$ & \multicolumn{2}{|c|}{$\begin{array}{l}\text { Cães com doença } \\
\text { renal crônica* }\end{array}$} \\
\hline Grupo & G1 & $\mathrm{G} 2$ & G3 \\
\hline Condição dos animais & Controle & DRC E1-2 & DRC E 3-4 \\
\hline Número de animais & 13 & 5 & 13 \\
\hline Número de observações & 39 & 13 & 16 \\
\hline Peso corporal (kg) & $14,52 \pm 4,32$ & $13,03 \pm 9,72$ & $23,08 \pm 9,77$ \\
\hline Creatinina sérica (mg/dl) & $0,94 \pm 0,18$ & $1,22 \pm 0,29$ & $6,44 \pm 4,92$ \\
\hline $\begin{array}{l}\text { Volume de urina } \\
(\mathrm{ml} / \mathrm{kg} / 24 \mathrm{~h})\end{array}$ & $17,23 \pm 6,33$ & $37,25 \pm 30,27$ & $39,74 \pm 7,35$ \\
\hline $\begin{array}{l}\text { Razão proteína/ } \\
\text { creatinina urinária }\end{array}$ & $0,17 \pm 0,07$ & $0,51 \pm 0,34$ & $1,68 \pm 1,64$ \\
\hline
\end{tabular}

* Classificação da doença renal crônica de acordo com o estabelecido pela International Renal Interest Society (IRIS 2006).

relativos à distribuição e caracterização dos animais que compuseram cada grupo estudado.

\section{Protocolo experimental}

Cada cão foi instalado em gaiola metabólica onde permaneceu por um período de 6 dias, sendo 3 dias para adaptação e outros 3 dias para avaliação experimental. Quanto aos pacientes com DRC, as avaliações foram feitas uma única vez (uma observação).

As avaliações realizadas compreenderam (1) concentração sérica de creatinina, cálcio, fósforo, sódio e potássio, (2) clearance de creatinina de 24 horas, (3) volume de urina de 24 horas, (4) excreção urinária de proteína, e (5) indicadores da participação renal na homeostase de cálcio, fósforo, sódio e potássio (carga filtrada, excreção fracionada e excreção urinária de cada eletrólito). As dosagens de creatinina sérica e urinária foram feitas pela reação de Jaffé modificada - picrato alcalino (Creatinina K Ref. $96^{4}$ ), em leitura cinética de dois pontos. A concentração urinária de proteína foi determinada pelo método do vermelho pirogalol ${ }^{4}$, com reação de ponto final. A quantificação do cálcio total, das amostras de soro e urina, foi feita por reação cromogênica com cresolftaleina complexona (Cálcio liquiform Ref. 90) ${ }^{4}$. As análises quantitativas de fósforo inorgânico sérico e urinário foram feitas pelo método fosfomolibdato (Fósforo Ref. $42^{4}$ ), em reação de ponto final. As leituras das análises bioquímicas foram feitas em fotômetro ${ }^{5}$. As concentrações séricas e urinárias de sódio e potássio e as concentrações séricas de cálcio iônico foram feitas pelo método de eletrodo íon-seletivo ${ }^{6}$. A perda de proteína na urina foi estimada pelo cálculo da razão proteína/creatinina urinária (U-P/C).

\section{Análise estatística}

Os dados obtidos foram submetidos à análise estatística descritiva para obtenção de média e desvio padrão. A distribuição foi analisada pelo teste de normalidade D'Agostino \& Pearson tendo sido verificadas tanto distribuição normal quanto não normal. Por não ter havido similaridade de distribuição entre os grupos, ficou contra-indicada a análise nãoparamétrica. Os dados foram, então, submetidos a transformação logarítimica (logaritimo natural, base e) e, subsequente-
Quadro 2. Regras adotadas para interpretação dos valores de P (Graphpad Prism version 5.00)

\begin{tabular}{lcc}
\hline Valor de P & Interpretação & Representação \\
\hline$<0,001$ & Extremamente significativo & $* \star *$ \\
0,001 a 0,01 & Muito significativo & $* *$ \\
0,01 a 0,05 & Significativo & $*$ \\
$>0,05$ & Não significativo & ns
\end{tabular}

mente, procedeu-se a análise de variância para dados não pareados (One-way ANOVA), seguida pelo teste de Tukey para comparação múltipla. O nível mínimo de significância foi estabelecido em $95 \%$ de probabilidade e a interpretação dos valores de P seguiram as regras apresentadas no Quadro 2. Todas as análises e gráficos foram realizados por meio do programa "Graphpad Prism version 5.00 for Windows", Graphpad Software, San Diego, California, USA.

\section{RESULTADOS}

$\mathrm{Na}$ avaliação da concentração sérica de creatinina, produção de urina, proteinúria e clearence de creatinina, que permitiram a caracterização dos animais do presente estudo, foram evidenciadas diferenças significativas nos cães dos três grupos (G1, G2, G3), as alterações destes parâmetros foram observadas tanto pela existência como pelo estadiamento da doença $(P<0,001)$. (Quadro 3, Fig.1)

As concentrações séricas de cálcio total apresentadas pelos três grupos não diferiram significativamente

Quadro 3. Médias, desvios padrões e dados estatísticos relativos à concentração sérica de creatinina (Scr), produção de urina (PUr), razão proteína/creatinina urinária (U-P/C) e clearance de creatinina de $24 \mathrm{~h}$ horas (Ccr) de cães sadios (G1) e de cães com doença renal crônica em estádio 1 ou 2 (G2) e em estádio 3 ou 4 (G3). Unesp-Jaboticabal, 2009

\begin{tabular}{|c|c|c|c|c|c|c|}
\hline \multirow{2}{*}{$\begin{array}{c}\text { Variáveis } \\
\text { analisadas }\end{array}$} & \multirow{2}{*}{$\begin{array}{l}\text { Gru- } \\
\text { pos }\end{array}$} & \multirow{2}{*}{$\begin{array}{c}\text { Média } \\
\pm \mathrm{DP}\end{array}$} & \multirow{2}{*}{$\begin{array}{c}\text { ANOVA } \\
\mathrm{P}\end{array}$} & \multicolumn{3}{|c|}{ Teste de Tukey } \\
\hline & & & & Comparaçõ & ões & IC \\
\hline & G1 & 18 & & $2 r$ & $\mathrm{~ns}$ & $-0,56$ \\
\hline \multirow[t]{2}{*}{$(\mathrm{mg} / \mathrm{dl})$} & $G$ & & 0,0001 & G3 * & & $-1,97$ \\
\hline & $G$ & & & & $\star * *$ & \\
\hline PUT & G1 & 11 & & 32 * & $\star * *$ & -0 \\
\hline \multirow[t]{2}{*}{$(\mu \mathrm{l} / \mathrm{min} / \mathrm{kg})$} & G2 & 25,8 & $<0,0001$ & a 3 * & $\star * * *$ & -1 , \\
\hline & G3 & & & & ns & -0 \\
\hline \multirow[t]{3}{*}{$U-P / C$} & G1 & & & 2 * & $* * *$ & $-1,43$ \\
\hline & G & & 01 & & 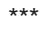 & \\
\hline & $\mathrm{G}$ & 1,6 & & G2 & *** & $-1,7$ \\
\hline & $\mathrm{G} 1$ & 3,0 & & $\mathrm{G} 1$ vsG2 * & $* * *$ & 0,37 a 0,85 \\
\hline \multirow{2}{*}{$(\mathrm{ml} / \mathrm{min} / \mathrm{kg})$} & G2 & 1,7 & $<0,0001$ & $\mathrm{G} 1 v s \mathrm{G} 3$ * & $* * *$ & 0,71 a 1,41 \\
\hline & G3 & $1,04 \pm 0,25$ & & G2vsG3 & * & 0,06 a 0,84 \\
\hline
\end{tabular}

$\overline{\mathrm{ns}}=$ Não significativo $(\mathrm{P}>0,05),{ }^{*}$ significativo $(\mathrm{P}$ entre 0,01 e 0,05$),{ }^{*}$ * muito significativo ( $P$ entre 0,001 e 0,01 ), ${ }^{* * *}$ extremamente significativo $(\mathrm{P}<0,001)$.

IC = intervalo de confiança para as diferenças das médias (95\%). O estágio da doença renal crônica está de acordo com o estabelecido pela International Renal Interest Society (IRIS 2006 staging CKD).

\footnotetext{
${ }^{4}$ Sensiprot@, Labtest Diagnóstica S.A., Av. Paulo Ferreira da Costa 600, Lagoa Santa, MG.

${ }^{5}$ Labquest ${ }^{\circledR}$, Labtest, Av. Paulo Ferreira da Costa 600, Lagoa Santa, MG.

${ }^{6}$ Drake Eletrônica e Comércio Ltda, Iselab Na/K/Ca, Av. Doutor Aniloel Nazareth 5770, São José do Rio Preto, SP.
} 
A

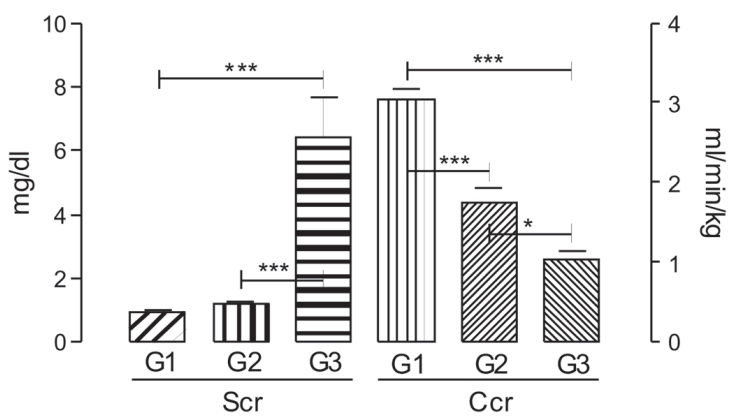

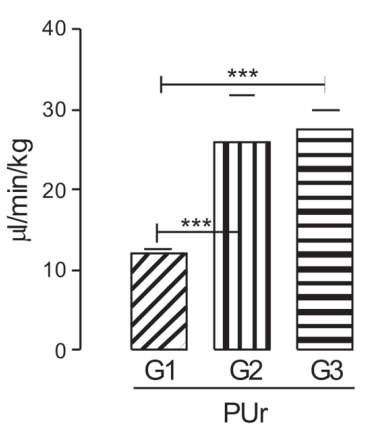

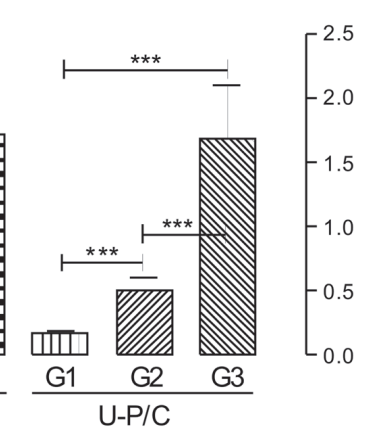

Fig.1. Representações gráficas das médias (colunas) e respectivos erros padrões (barras nos topos das colunas) e dos resultados das análises estatísticas de parâmetros relacionados à função renal em cães normais (G1), cães com DRC E1-2 (G2) e cães com DRC E3-4 (G3). A - concentração sérica de creatinina (Scr) e clearance de creatinina de 24 horas (Ccr). B - produção de urina (PUr) e razão proteína/creatinina urinária $(\mathrm{U}-\mathrm{P} / \mathrm{C})$. As diferenças estatisticamente significativas entre as médias dos grupos, para cada parâmetro, estão assinaladas por barras horizontais encimadas pelo indicativo de probabilidade ( ${ }^{*} \mathrm{P}$ de 0,01 a 0,$05 ;{ }^{* *} \mathrm{P}$ de 0,001 a 0,01; $\left.{ }^{* * *} \mathrm{P}<0,001\right)$. Unesp-Jaboticabal, 2009.

entre si $(P>0,05)$. Entretanto, a média de SCai do grupo G3 foi significativamente maior do que a do grupo G1 $(P<0,01)$ e $G 2(P<0,05)$. A média de concentração sérica de fósforo do grupo $\mathrm{G} 3$ foi significativamente maior que as dos grupos controle $(P<0,001)$ e $G 2(P<0,01)$. A concentração sérica de sódio do grupo G3 foi significativamente menor do que as médias dos grupos controle e G2 $(P<0,001)$. As médias de concentração sérica de potássio dos três grupos não diferiram significativamente entre si $(P>0,05)$ (Quadro 4, Fig.2). Já a média dos percentuais de cálcio iônico sérico em relação ao cálcio total sérico do grupo G3 foi significativamente menor que as demais

\section{Quadro 4. Médias, desvios padrões e dados estatísticos das concentrações séricas de cálcio total (SCat), cálcio iônico (SCai), fósforo (SP), sódio (SNa) e potássio (SK) de cães sadios (G1) e de cães com doença renal crônica em estádio 1 ou 2 (G2) e em estádio 3 ou 4 (G3). Unesp-Jaboticabal, 2009}

\begin{tabular}{|c|c|c|c|c|c|c|}
\hline \multirow{2}{*}{$\begin{array}{l}\text { Variáveis } \\
\text { analisadas }\end{array}$} & \multirow{2}{*}{$\begin{array}{c}\text { Gru- } \\
\text { pos }\end{array}$} & \multirow{2}{*}{$\begin{array}{c}\text { Média } \\
\pm \mathrm{DP}\end{array}$} & \multirow{2}{*}{$\begin{array}{c}\text { ANOVA } \\
P\end{array}$} & \multicolumn{3}{|c|}{ Teste de Tukey } \\
\hline & & & & Comparaçõ & ões & IC \\
\hline crot & c & $1069+$ & \multirow{3}{*}{0,7069} & CS? & ns & $-0,08$ a 0, \\
\hline \multirow[t]{2}{*}{$(\mathrm{mg} / \mathrm{dl})$} & & & & & ns & \\
\hline & & & & & ns & \\
\hline & & & & & ns & \\
\hline \multirow[t]{2}{*}{$(\mathrm{mmol} / \mathrm{L})$} & & & \multirow[t]{2}{*}{0,0056} & & ** & \\
\hline & & & & $G$ & * & \\
\hline \multirow{3}{*}{$\begin{array}{c}\mathrm{SP} \\
(\mathrm{mg} / \mathrm{dl})\end{array}$} & & & \multirow{3}{*}{$<0,0001$} & G1 & ns & $-C$ \\
\hline & 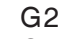 & & & G1vsG3 & $\star \star \star$ & -0 \\
\hline & $G$ & & & G2vsG3 & ** & -0 \\
\hline & G1 & 145 & & G1 vsG2 & ns & $-0,03$ a 0,02 \\
\hline \multirow{2}{*}{$(\mathrm{mEq} / \mathrm{L})$} & G & 145 & \multirow[t]{2}{*}{$<0,0001$} & G1vsG3 & $* * *$ & 4 a 0,08 \\
\hline & & & & & *** & \\
\hline \multirow{3}{*}{$\begin{array}{c}\mathrm{SK} \\
(\mathrm{mEq} / \mathrm{L})\end{array}$} & G & & \multirow{3}{*}{0,6292} & G1vsG2 & ns & $-0,10$ a 0,07 \\
\hline & $\mathrm{G}$ & & & G1vsG3 & ns & $-0,11$ a $-0,05$ \\
\hline & G3 & 4,6 & & G2vsG3 & ns & 0,09 \\
\hline
\end{tabular}

ns $=$ Não significativo $(P>0,05),{ }^{*}$ significativo $(P$ entre 0,01 e 0,05$),{ }^{*}$ muito significativo (P entre 0,001 e 0,01 ), ${ }^{* *}$ extremamente significativo $(\mathrm{P}<0,001)$.

IC = intervalo de confiança para as diferenças das médias (95\%). O estágio da doença renal crônica está de acordo com o estabelecido pela International Renal Interest Society (IRIS 2006 staging CKD).
A

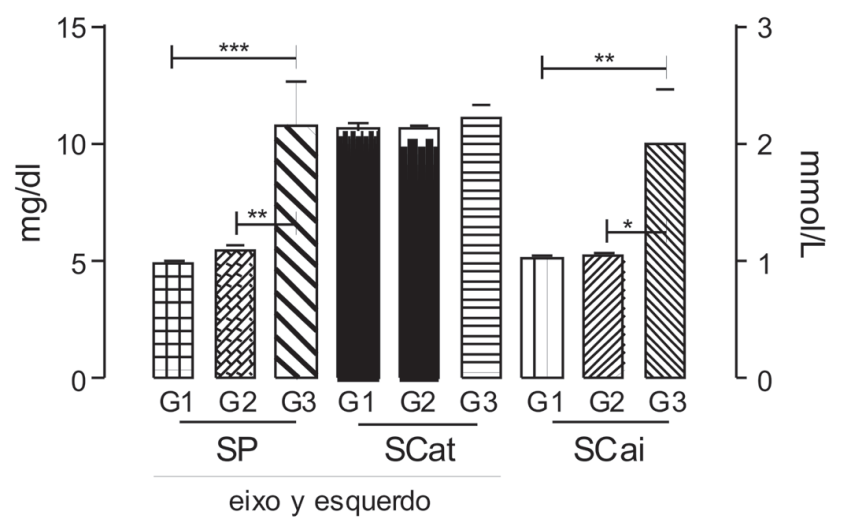

B

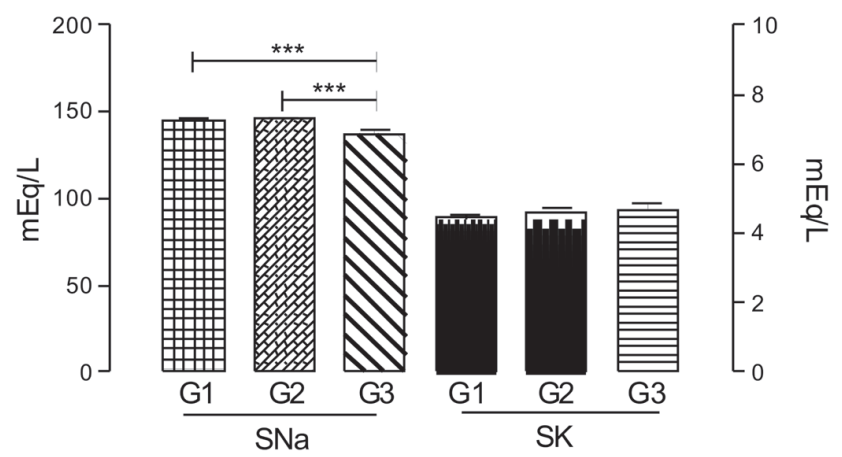

Fig.2. Representações gráficas das médias (colunas) e respectivos erros padrões (barras verticais nos topos das colunas) e dos resultados das análises estatísticas de parâmetros relacionados às concentrações séricas de: $(A)$ fósforo (SP), cálcio total (SCat) e cálcio iônico (SCai), e (B) sódio (SNa) e potássio (SK), avaliados em cães normais (G1), cães com DRC E1-2 (G2) e cães com DRC E3-4 (G3). As diferenças estatisticamente significativas entre as médias dos grupos, para cada parâmetro, estão assinaladas por barras horizontais encimadas pelo indicativo de probabilidade ( ${ }^{*} \mathrm{P}$ de 0,01 a 0,$05 ;{ }^{* *} \mathrm{P}$ de 0,001 a 0,$01 ;{ }^{* * *}$ $\mathrm{P}<0,001)$. Unesp-Jaboticabal, 2009. 
$(P<0,05)$. As análises dos resultados das razões SCai/P e SCat/P revelaram o mesmo comportamento. As médias do grupo G3 foram significativamente menores do que as médias dos grupos controle e $\mathrm{G} 2(\mathrm{P}<0,001)$. Quanto à razão $\mathrm{SNa} / \mathrm{K}$, a média do grupo $\mathrm{G} 3$ foi significativamente menor do que a obtida no grupo controle $(P<0,05)$ (Quadro 5, Fig.3).

A quantidade de cálcio iônico filtrada pelos glomérulos

\begin{abstract}
Quadro 5. Médias, desvios padrões e dados estatísticos do percentual de cálcio iônico em relação ao cálcio total sérico (SCai/Cat) e das razões séricas de cálcio total/ fósforo (SCat/P), cálcio iônico/fósforo (SCai/P) e sódio/ potássio (SNa/K) e de cães sadios (G1) e de cães com doença renal crônica em estádio 1 ou 2 (G2) e em estádio 3 ou 4 (G3). Unesp-Jaboticabal, 2009
\end{abstract}

\begin{tabular}{|c|c|c|c|c|c|c|}
\hline \multirow{2}{*}{$\begin{array}{l}\text { Variáveis } \\
\text { analisadas }\end{array}$} & \multirow{2}{*}{$\begin{array}{l}\text { Gru- } \\
\text { pos }\end{array}$} & \multirow{2}{*}{$\begin{array}{l}\text { Média } \\
\pm \mathrm{DP}\end{array}$} & \multirow{2}{*}{$\begin{array}{c}\text { ANOVA } \\
\mathrm{P}\end{array}$} & \multicolumn{3}{|c|}{ Teste de Tukey } \\
\hline & & & & Comparaç & ões & IC \\
\hline \multirow{3}{*}{$\begin{array}{c}\text { SCai/Cat } \\
(\%)\end{array}$} & $\mathrm{G} 1$ & 39,1 & & & ns & $-0,15 a$ \\
\hline & G2 & 39,6 & 0,0134 & G1vsG3 & & 0,03 a 0,32 \\
\hline & G3 & $33,26 \pm 7,93$ & & G2vsG3 & * & 0,02 a 0,37 \\
\hline \multirow[t]{3}{*}{ SCai/P } & $\mathrm{G} 1$ & 0,8 & & G1 vsG2 & ns & $-0,40$ a 0,54 \\
\hline & $\mathrm{G}$ & & $<0,0001$ & G1 vsG3 & $\star \star * *$ & 0,66 a 1,60 \\
\hline & G3 & 0,4 & & sG3 & $\star * *$ & 0,48 a 1,63 \\
\hline \multirow[t]{3}{*}{ SCat/P } & $\mathrm{G} 1$ & 2,22 & & G1 vsG2 & ns & $-0,22$ a 0,40 \\
\hline & G2 & 1,97 & $<0,0001$ & G1vsG3 & $* * *$ & 0,27 a 0,84 \\
\hline & G3 & $1,55 \pm 1,05$ & & G2vsG3 & $\star \star$ & 0,11 a 0,82 \\
\hline \multirow[t]{3}{*}{$\mathrm{SNa} / \mathrm{K}$} & G1 & $32,61 \pm 2,82$ & & G1 vsG2 & ns & $-0,08$ a 0,11 \\
\hline & G2 & $32,19 \pm 3,54$ & 0,0445 & G1 vsG3 & * & 0,01 a 0,18 \\
\hline & G3 & $30,07 \pm 5,24$ & & G2vsG3 & ns & $-0,03$ a 0,19 \\
\hline
\end{tabular}

ns $=$ Não significativo $(P>0,05),{ }^{*}$ significativo $(P$ entre 0,01 e 0,05$),{ }^{*}$ muito significativo ( $P$ entre 0,001 e 0,01 ), ${ }^{* * *}$ extremamente significativo $(\mathrm{P}<0,001)$.

IC = intervalo de confiança para as diferenças das médias $(95 \%)$. O estágio da doença renal crônica está de acordo com o estabelecido pela International Renal Interest Society (IRIS 2006 staging CKD).

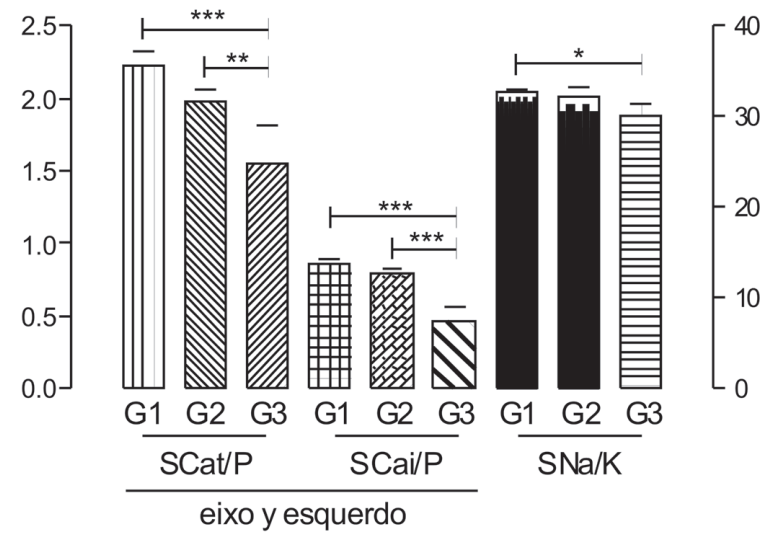

Fig.3. Representações gráficas das médias (colunas) e respectivos erros padrões (barras nos topos das colunas) e dos resultados das análises estatísticas dos valores da razão cálcio total/fósforo sérico (SCat/P) razão cálcio iônico/fósforo séricos (SCai/P) e razão sódio/potássio séricos em cães normais (G1), cães com DRC E1-2 (G2) e cães com DRC E3-4 (G3). As diferenças estatisticamente significativas entre as médias dos grupos, para cada parâmetro, estão assinaladas por barras horizontais encimadas pelo indicativo de probabilidade ( $\mathrm{P}$ de 0,01 a 0,$05 ;{ }^{* *} \mathrm{P}$ de 0,001 a 0,$01 ;{ }^{* * *} \mathrm{P}<0,001$ ). Unesp-Jaboticabal, 2009. foi significativamente menor nos cães com $D R C(P<0,001)$, mas não houve diferença significativa entre os grupos $G 2$ e G3 $(P>0,05)$. A excreção fracionada de cálcio foi significativamente maior nos dois grupos com DRC e, comparados os dois, foi significativamente maior no DCR G3 $(\mathrm{P}<0,001)$. Contudo, a quantidade de cálcio excretado na urina não diferiu significativamente entre os grupos, embora a média de CaEx do grupo $\mathrm{G} 3$ foi maior do que as outras ( $P>0,05$ ) (Quadro 6, Fig.4).

\section{Quadro 6. Médias, desvios padrões e dados estatísticos da carga filtrada de cálcio iônico (CFCai), excreção fracionada de cálcio (EFCa) e cálcio excretado na urina (CaiEx) de cães sadios (G1) e de cães com doença renal crônica em estádio 1 ou 2 (G2) e em estádio 3 ou 4 (G3). Unesp-Jaboticabal, 2009}

\begin{tabular}{|c|c|c|c|c|c|c|}
\hline \multirow{2}{*}{$\begin{array}{l}\text { Variáveis } \\
\text { analisadas }\end{array}$} & \multirow{2}{*}{$\begin{array}{c}\text { Gru- } \\
\text { pos }\end{array}$} & \multirow{2}{*}{$\begin{array}{c}\text { Média } \\
\pm \mathrm{DP}\end{array}$} & \multirow{2}{*}{$\begin{array}{c}\text { ANOVA } \\
\mathrm{P}\end{array}$} & \multicolumn{3}{|c|}{ Teste de Tukey } \\
\hline & & & & Compar & ões & IC \\
\hline & $\mathrm{G}_{1}$ & 126 & & G2 & *** & , \\
\hline \multirow[t]{2}{*}{$(\mu \mathrm{g} / \mathrm{min} / \mathrm{kg})$} & G2 & & \multirow{2}{*}{$<0,0001$} & G1vsG3 & *** & \\
\hline & G3 & 46,6 & & G2vsG3 & ns & 0,82 \\
\hline \multirow{3}{*}{$\begin{array}{c}\text { EFCa } \\
(\%)\end{array}$} & G1 & 1,2 & \multirow{3}{*}{$<0,0001$} & G1 vsG2 & * & 0,01 \\
\hline & G2 & $2,70 \pm$ & & G1vsG3 & $* \star *$ & $-3,43$ a $-2,06$ \\
\hline & G3 & $38,49 \pm 4$ & & G2vsG3 & $* \star \star$ & $-2,95$ a $-1,34$ \\
\hline \multirow{3}{*}{$\begin{array}{c}\text { CaiEx } \\
(\mu \mathrm{g} / \mathrm{min} / \mathrm{kg})\end{array}$} & G1 & $1,47 \pm 0,71$ & \multirow{3}{*}{0,0891} & G1vsG2 & ns & $-0,41$ a 0,39 \\
\hline & G2 & $1,54 \pm 0,83$ & & G1vsG3 & ns & $-1,14$ a 0,05 \\
\hline & G3 & $2,50 \pm 1,14$ & & G2vsG3 & ns & $-1,20$ a 0,12 \\
\hline
\end{tabular}

ns $=$ Não significativo $(P>0,05),{ }^{*}$ significativo $(P$ entre 0,01 e 0,05$)$, ** muito significativo (P entre 0,001 e 0,01$)$, ${ }^{* * *}$ extremamente significativo $(\mathrm{P}<0,001)$.

IC = intervalo de confiança para as diferenças das médias (95\%).

O estágio da doença renal crônica está de acordo com o estabelecido pela International Renal Interest Society (IRIS 2006 staging CKD).

A carga filtrada de fósforo dos cães com DRC foi significativamente menor do que a dos cães normais $(P<0,001)$. A EFP do grupo G3 foi significativamente maior do que as médias dos grupos controle $(P<0,001)$ e $G 2(P<0,05)$. Contudo, as médias de PEx dos três grupos não diferiram significativamente entre si $(P>0,05)$ (Quadro 7, Fig.4).

As médias de carga filtrada de sódio dos cães com DRC foram significativamente menores do que a do grupo controle e também diferiram entre si, sendo significativamente menor a média do grupo $G 3(P<0,001)$. A média de excreção fracionada de sódio do grupo G3 foi significativamente maior que as dos animais normais e a do G2 $(\mathrm{P}<0,001)$. As médias das quantidades de sódio excretadas na urina não diferiram significativamente entre si $(P>0,05)$ (Quadro 8, Fig.5).

As médias de carga filtrada de potássio dos cães com DRC foram significativamente menores do que a do grupo controle $(P<0,001)$, e também diferiram significativamente entre si, sendo menor a média do grupo $G 3(P<0,01)$. $A$ média de excreção fracionada de potássio do grupo G3 foi significativamente maior que as dos animais normais ( $P<0,001)$ e a do grupo $G 2$ que, por sua vez foi menor que a do grupo controle $(P<0,01)$. As médias das quantidades de potássio excretadas na urina não diferiram significativamente entre si $(P>0,05)$ (Quadro 9, Fig.5). 
A

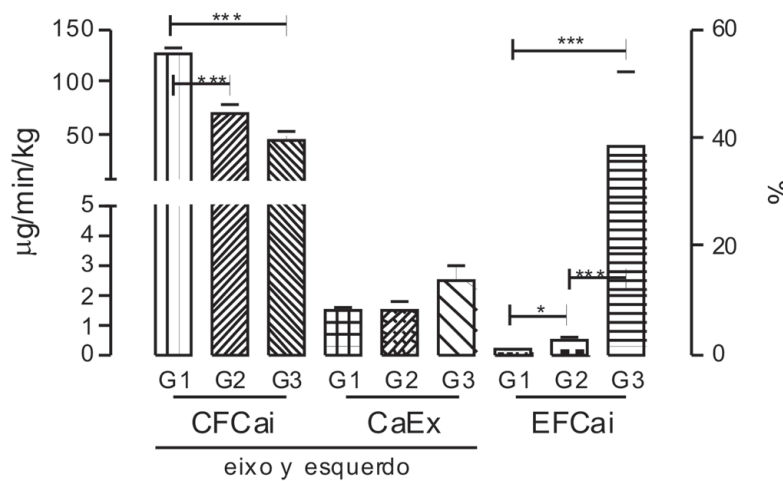

B

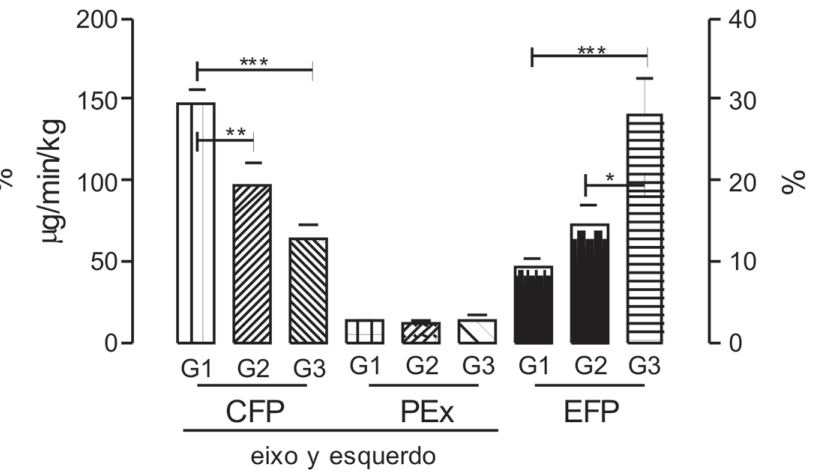

Fig.4. Representações gráficas das médias (colunas) e respectivos erros padrões (barras nos topos das colunas) e dos resultados das análises estatísticas de parâmetros relacionados à filtração, reabsorção e excreção renal de eletrólitos, avaliados em cães normais (G1), cães com DRC E1-2 (G2) e cães com DRC E3-4 (G3). (A) Carga filtrada de cálcio iônico (CFCai), cálcio iônico excretado (CaiEx) e excreção fracionada de cálcio iônico (EFCai). (B) Carga filtrada de fósforo (CFP), fósforo excretado (PEx) e excreção fracionada de fósforo (EFP). As diferenças estatisticamente significativas entre as médias dos grupos, para cada parâmetro, estão assinaladas por barras horizontais encimadas pelo indicativo de probabilidade $\left({ }^{*} \mathrm{P}\right.$ de 0,01 a 0,$05 ;{ }^{* *} \mathrm{P}$ de 0,001 a 0,$\left.01 ;{ }^{* \star *} P<0,001\right)$. UNESP - Jaboticabal, 2009.

\begin{abstract}
Quadro 7. Médias, desvios padrões e dados estatísticos da carga filtrada de fósforo (CFP), excreção fracionada de fósforo (EFP) e fósforo excretado na urina (PEx) de cães sadios (G1) e de cães com doença renal crônica em estádio 1 ou 2 (G2) e em estádio 3 ou 4 (G3). UnespJaboticabal, 2009
\end{abstract}

\begin{tabular}{|c|c|c|c|c|c|c|}
\hline \multirow{2}{*}{$\begin{array}{c}\text { Variáveis } \\
\text { analisadas }\end{array}$} & \multirow{2}{*}{$\begin{array}{l}\text { Gru- } \\
\text { pos }\end{array}$} & \multirow{2}{*}{$\begin{array}{l}\text { Média } \\
\pm \mathrm{DP}\end{array}$} & \multirow{2}{*}{$\begin{array}{c}\text { ANOVA } \\
\mathrm{P}\end{array}$} & \multicolumn{3}{|c|}{ Teste de Tukey } \\
\hline & & & & Comparaçõe & 5es & IC \\
\hline . & G1 & 1 & & 2 & ** &, 80 \\
\hline \multirow[t]{2}{*}{$(\mu \mathrm{g} / \mathrm{min} / \mathrm{kg})$} & G2 & & $<0,0001$ & द 3 ** & *** & \\
\hline & G3 & & & $3 n$ & ns & -0 \\
\hline EF & G1 & & & $2 n$ & ns & -0 , \\
\hline \multirow[t]{2}{*}{$(\%)$} & G2 & 14,7 & $<0,0001$ & G1vsG3 ** & *** - & a $-0,6$ \\
\hline & G3 & 28,1 & & G2v & ${ }^{*}-$ & $-1,25$ a $-0,0$ \\
\hline & $\mathrm{G} 1$ & $12,94 \pm 6,26$ & & $\mathrm{G} 1$ vsG2 $\mathrm{n}$ & ns & $-0,44$ a 0,49 \\
\hline \multirow{2}{*}{$(\mu \mathrm{g} / \mathrm{min} / \mathrm{kg})$} & $\mathrm{G} 2$ & 12,4 & 0,9879 & G1vsG3 $\mathrm{n}$ & ns & $-0,69$ a 0,67 \\
\hline & G3 & $13,60 \pm 7,97$ & & G2vsG3 $\mathrm{n}$ & ns & $-0,79$ a 0,71 \\
\hline
\end{tabular}

ns $=$ Não significativo $(P>0,05),{ }^{*}$ significativo $(P$ entre 0,01 e 0,05$),{ }^{* *}$ muito significativo (P entre 0,001 e 0,01$)$, ${ }^{* *}$ extremamente significativo $(P<0,001)$.

$I C=$ intervalo de confiança para as diferenças das médias (95\%). O estágio da doença renal crônica está de acordo com o estabelecido pela International Renal Interest Society (IRIS 2006 staging CKD).

\section{DISCUSSÃO}

Os resultados obtidos na concentração sérica de creatinina em animais do grupo G3 indicaram comprometimento de mais de $75 \%$ da função renal (Finco \& Duncan 1976). Resultados semelhantes foram observados correlacionando o declínio da função glomerular e a pressão arterial, descrevendo assim que a diminuição da TFG varia inversamente proporcional a concentração sérica de creatinina (Bodey \& Mitchel 1996).

Pacientes com insuficiência renal crônica apresentam poliúria como consequência da perda da capacidade de conservar água (Finco 1995). Em cães a presença de poliúria com polidipsia compensatória está entre as primeiras manifestações clínicas de IRC (Polzin \& Osborne 1995). Os grupos de cães com doença renal crônica pro-
Quadro 8. Médias, desvios padrões e dados estatísticos da carga filtrada de sódio (CFNa), excreção fracionada de sódio (EFNa) e sódio excretado na urina ( $\mathrm{NaEx}$ ) de cães sadios (G1) e de cães com doença renal crônica em estádio 1 ou 2 (G2) e em estádio 3 ou 4 (G3). UnespJaboticabal, 2009

\begin{tabular}{|c|c|c|c|c|c|}
\hline \multirow{2}{*}{$\begin{array}{c}\text { Variáveis } \\
\text { analisadas }\end{array}$} & \multirow{2}{*}{$\begin{array}{l}\text { Gru- } \\
\text { pos }\end{array}$} & \multirow{2}{*}{$\begin{array}{l}\text { Média } \\
\pm \mathrm{DP}\end{array}$} & \multirow{2}{*}{$\begin{array}{c}\text { ANOVA } \\
\mathrm{P}\end{array}$} & \multicolumn{2}{|c|}{ Teste de Tukey } \\
\hline & & & & Comparações & IC \\
\hline CFNa & G & 0 & & 2 & 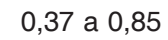 \\
\hline$(\mu \mathrm{Eq} / \mathrm{m}$ & G2 & & $<0,0001$ & $3^{* \star *}$ & \\
\hline & G3 & & & $\mathrm{G}$ & \\
\hline & G1 & & & G1 vsG2 * & $8 a$ \\
\hline & G2 & 0,6 & $<0,0001$ & G1vsG3 *** & $8 a$ \\
\hline & G3 & 4,7 & & a 3 *** & a -0, \\
\hline & G1 & 12,6 & & G1 vsG2 ns & $-0,35$ a 0,24 \\
\hline$(\mu \in q / m$ & $\mathrm{G} 2$ & 13 & 0,7036 & G1vsG3 ns & $-0,32$ a 0,56 \\
\hline & G3 & $10,75 \pm 2,18$ & & G2vsG3 ns & $-0,32$ a 0,66 \\
\hline
\end{tabular}

$\overline{n s}=$ Não significativo $(P>0,05),{ }^{*}$ significativo $(P$ entre 0,01 e 0,05$)$, * * muito significativo (P entre 0,001 e 0,01 ), ${ }^{* * *}$ extremamente significativo $(P<0,001)$.

IC = intervalo de confiança para as diferenças das médias (95\%).

O estágio da doença renal crônica está de acordo com o estabelecido pela International Renal Interest Society (IRIS 2006 staging CKD).

duziram quantidades de urina significativamente maiores do que os cães normais. Afirmando que a poliúria ocorre quando dois terços da capacidade funcional de ambos os rins encontra-se prejudicada (Rubin 1997).

A intensidade da proteinúria foi modificada tanto pela existência da doença como pelo estadiamento da DRC. A proteinúria persistente de origem renal é um importante marcador de enfermidade renal crônica em cães e gatos. Um estudo desenvolvido em cães demonstrou que valores de UP/C normais estão entre 0,2 e 0,3 ou menos (Grauer et al.1985). Proteinúria persistente com valores de UP/C entre 0,4 e 0,5 em cães e gatos, quando descartada proteinúria pré-renal ou pós-renal, é considerada como um sinal de doença renal crônica glomerular ou túbulo-intersticial. Já UP/C maiores de 2,0 são fortemente sugestivos de 
A

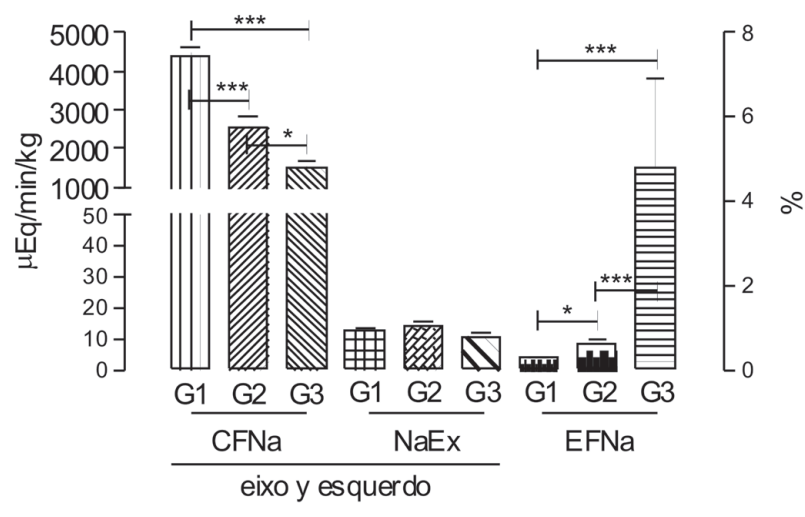

B

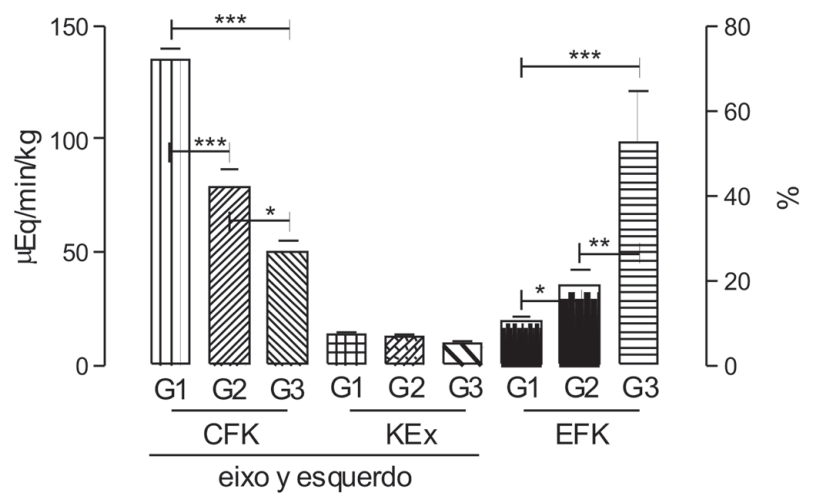

Fig.5. Representações gráficas das médias (colunas) e respectivos erros padrões (barras nos topos das colunas) e dos resultados das análises estatísticas de parâmetros relacionados à filtração, reabsorção e excreção renal de eletrólitos, avaliados em cães normais (G1), cães com DRC E1-2 (G2) e cães com DRC E3-4 (G3). (A) Carga filtrada de sódio (CFNa), sódio excretado ( $\mathrm{NaEx}$ ) e excreção fracionada de sódio (EFNa). (B) Carga filtrada de potássio (CFK), potássio excretado (KEx) e excreção fracionada de potássio (EFK). As diferenças estatisticamente significativas entre as médias dos grupos, para cada parâmetro, estão assinaladas por barras horizontais encimadas pelo indicativo de probabilidade ( ${ }^{*} \mathrm{P}$ de 0,01 a 0,$05 ;{ }^{*} \mathrm{P}$ de 0,001 a 0,$\left.01 ;{ }^{* \star} P<0,001\right)$. Unesp-Jaboticabal, 2009.

enfermidade glomerular (Grauer 2007, Newman et al. 2000). Estudos em pacientes humanos com proteinúria sugestiva de enfermidade renal sugerem que a mesma está relacionada com a progressão da doença (Grauer 2007).

Os achados anteriormente descritos, que permitiram a caracterização das condições dos animais estudados, foram confirmados pelo clearence de creatinina. Os valores de Ccr foram significativamente menores para os animais doentes que para os animais do grupo controle, os animais do grupo G3 com maior comprometimento renal, apresentaram médias de Ccr significativamente menores que as dos demais grupos de animais. É considerado que para propósitos clínicos a obtenção de valores de Ccr é suficiente para indicar o comprometimento da função glomerular (Bovée \& Joice 1979). Os valores de Ccr de pacientes com insuficiência renal crônica naturalmente adquirida são
Quadro 9. Médias, desvios padrões e dados estatísticos da carga filtrada de potássio (CFK), excreção fracionada de potássio (EFK) e potássio excretado na urina (KEx) de cães sadios (G1) e de cães com doença renal crônica em estádio 1 ou 2 (G2) e em estádio 3 ou 4 (G3). UnespJaboticabal, 2009

\begin{tabular}{|c|c|c|c|c|c|}
\hline \multirow{2}{*}{$\begin{array}{l}\text { Variáveis } \\
\text { analisadas }\end{array}$} & \multirow{2}{*}{$\begin{array}{l}\text { Gru- } \\
\text { pos }\end{array}$} & \multirow{2}{*}{$\begin{array}{l}\text { Média } \\
\pm \mathrm{DP}\end{array}$} & \multirow{2}{*}{$\begin{array}{c}\text { ANOVA } \\
\mathrm{P}\end{array}$} & \multicolumn{2}{|c|}{ Teste de Tukey } \\
\hline & & & & Comparações & IC \\
\hline CFK & G1 & 13 & & 2 & 1 \\
\hline \multirow[t]{2}{*}{$(\mu \mathrm{Eq} / \mathrm{min} / \mathrm{kg})$} & $\mathrm{G} 2$ & & $<0,0001$ & $1 \mathrm{G}$ & \\
\hline & G3 & & & 3 & \\
\hline & $\mathrm{G} 1$ & & & 2 * & -0 \\
\hline \multirow[t]{2}{*}{$(\%)$} & G2 & 18 & $<0,0001$ & $3^{* * *}$ & -1 \\
\hline & G3 & & & 3 ** & -1 \\
\hline \multirow{3}{*}{$\begin{array}{c}\text { KEX } \\
(\mu \mathrm{Eq} / \mathrm{min} / \mathrm{kg})\end{array}$} & G1 & 13 & & $12 \mathrm{~ns}$ & $-0,28$ a 0,37 \\
\hline & $\mathrm{G} 2$ & 12 , & 0,2536 & $3 \mathrm{~ns}$ & -0 \\
\hline & G3 & 9,1 & & G2vsG3 ns & $-0,25$ a $0, \varepsilon$ \\
\hline
\end{tabular}

$\overline{\mathrm{ns}}=$ Não significativo $(\mathrm{P}>0,05),{ }^{*}$ significativo $(\mathrm{P}$ entre 0,01 e 0,05$),{ }^{*}$ * muito significativo (P entre 0,001 e 0,01 ), ${ }^{* * *}$ extremamente significativo $(P<0,001)$.

IC = intervalo de confiança para as diferenças das médias (95\%).

O estágio da doença renal crônica está de acordo com o estabelecido pela International Renal Interest Society (IRIS 2006 staging CKD).

substancialmente menores que aqueles dos cães com função renal normal (Bovée \& Joice 1979).

Em relação às concentrações séricas de cálcio total, os achados do presente estudo diferiram de outros resultados, no qual a concentração sérica de Cai foi significativamente inferior no grupo de cães com IRC que no grupo de cães normais. A concentração sérica de Cai pode ser influenciada por diferentes estados dentre os quais são destacados a acidose e alcalose metabólica, sem desenvolver alterações na concentração sérica de cálcio total (Kojika et al. 2006). A concentração de cálcio iônico em cães com insuficiência renal crônica varia amplamente da concentração de cálcio total mostrando a importância de determinar a fração biologicamente ativa do cálcio (Kojika et al. 2006). A dosagem de Cai em cães tem se mostrado superior a mensuração de Cat do soro em várias condições, em especial em casos de hiperparatiroidismo, doença renal, hipo e hiperproteinemia, entre outros (Schenk \& Chew 2005) Em estudo realizado foi evidenciado em gatos com IRC, aumentos na concentração sérica de Cai, como neste estudo, já os valores séricos de cálcio total observados nos gatos com IRC não diferiram daqueles observados no grupo controle (Giovaninni 2003). Outro estudo em cães, também não observou diferenças nas concentrações de cálcio total, mas não foram consideradas as concentrações de Cai (Bienzle1993).

A excreção do íon fosfato diminui com a redução da TFG (Polzin \& Osborne 1995, Brown et al. 1997). Como descrito, animais em estágio avançado de doença renal apresentam concentrações elevadas de fósforo pela incapacidade de excreção dos rins quando diminui a TFG (Barber \& Elliott 1998). Em estudo desenvolvido, detectou-se hiperfosfatemia em $92 \%$ dos cães do grupo com IRC (Kojika et al 2006)

Pacientes com insuficiência renal crônica sofrem alterações importantes que comprometem a homeostase do 
sódio. Em estudo, animais com IRC com perda severa de sódio apresentam lesão renal caracteristicamente túbulointersticial crônica, mas pacientes com lesões predominantemente glomerulares apresentam a forma suave de perda de sódio (Toto \& Seldin 1992). A perda da capacidade de manter o balanço de sódio na IRC ocorre quando a TFG cai para menos do que $10 \%$ do valor normal (Frommer \& Kurtzman 1984). Concentrações séricas de sódio em animais insuficientes renais crônicos significativamente menores em relação aos animais normais já foram evidenciados (Chew \& Dibartola 1992).

No entanto as concentrações séricas de potássio dos três grupos não apresentaram diferenças significativas, isso em parte, pode ser atribuído ao fato de que em estágios tardios da IRC os mecanismos tubulares compensatórios são capazes de manter a homeostase do potássio (Chew \& Dibartola 1992). Em outro estudo, também não foi observado diferenças significativas entre gatos sadios e gatos com doença renal crônica para os valores de potássio (Giovaninni 2003).

A média dos porcentuais séricos de Cai em relação ao Cat do grupo G3 foi significativamente menor que as demais. Animais em estágios avançados de IRC apresentam alteração na reabsorção tubular de cálcio (Polzin \& Osborne 1995). Apesar da concentração total de cálcio tender a refletir o Cai no sangue, esta relação se perde com frequência nos casos de IR (Chew \& Nagode 1990). Em estudo feito, houve discordância de $55 \%$ da predição de Cai a partir do Cat em cães com IRC e a hipocalcemia foi mais frequente em cães com IRC do que em outras doenças (Schenk \& Chew 2005).

O grupo de animais G3 apresentou médias significativamente menores que as médias dos outros grupos quanto a razão SCai/P e SCat/P. Em fases tardias da IRC distúrbios hidroeletrolíticos podem ser observados incluindo perturbações da homeostase do cálcio e fósforo. Outros autores observaram correlação negativa entre Cai e concentração de fósforo, atribuindo o fato de que a hiperfosfatemia poderia contribuir para o aumento da concentração de complexos de cálcio e, por conseguinte, alteração na concentração de Cai. Além da hiperfosfatemia, outros fatores como a acidose e outros compostos presentes em pacientes em estado urêmico podem alterar a concentração de Cai, contribuindo para a formação de complexos com cálcio (Kojika et al 2006).

No presente estudo, animais do grupo G3 apresentaram aumento das concentrações séricas de Cai e fósforo, e a razão destes se mostrou alterada neste grupo de animais. A alteração no metabolismo do cálcio e fósforo pode ocasionar precipitação de fosfato de cálcio em tecidos moles, que também ocorre no próprio tecido renal, desenvolvendo nefrocalcinose. Como resultado disso, ocorre a destruição do parênquima, agravando ainda mais o quadro de IRC (Zats 2000).

As concentrações séricas de sódio e potássio são mantidas no organismo dentro de estreita variação e para a manutenção de sua homeostase grande parte do sódio e potássio filtrado são reabsorvidos (De Morais \& Chew 1992). Em achados observados neste estudo a razão entre a concentração sérica de sódio e potássio do grupo G3 foi significativamente menor que a razão do grupo controle. O presente estudo indica para a avaliação da função renal a dosar as concentrações séricas de sódio e potássio; contudo, foi observado que a capacidade reguladora dos cães faz com que as alterações séricas só ocorram tardiamente. Além disso, o mecanismo tubular compensatório é capaz de manter a homeostase de sódio e potássio até estágios tardios de IRC (Chew \& Dibartola 1992). O presente estudo evidenciou que o grau com que os solutos aparecem na urina varia de acordo com a necessidade de manutenção da homeostase hídrica e eletrolítica do organismo.

Os cães com DRC apresentaram diminuição da carga filtrada de eletrólitos o que foi compensado pelo aumento da excreção fracionada. Isto, de igual forma, já foi evidenciando em cães, em que a $\mathrm{EFe}(\mathrm{Na}, \mathrm{K}, \mathrm{Cl}$ e $\mathrm{Mg})$ foi mas elevada nos azotêmicos, quase todos os cães com alteração renal, de moderada a severa apresentaram valores anormais na excreção destes eletrólitos (Buranakarl et al. 2007). Os mesmos autores observaram correlação entre creatinina no soro e EFe, sugerindo que a EFe possa ser um bom indicador de grau de redução da TFG. Quanto mais alta a EFe mais defeituoso é o transporte das células tubulares renais, especialmente no túbulo proximal (Finco 1995) . Também, um aumento na EFe indica o comprometimento na homeostase dos eletrólitos (Buranakarl et al. 2007). Além disso, a estimação da EFe através da urina, pode, muitas vezes, ser importante no monitoramento da doença ou de uma condição particular (McCaw et al. 1989).

Neste estudo animais do grupo G3 com lesões renais mais severas, apresentaram alteração nos indicadores de excreção renal dos elétrolitos estudados, conforme evidenciado em outros estudos (Zats 2000, Hayslett 1979).

As alterações na excreção renal referentes ao cálcio e ao fósforo, observadas em cães do grupo G3, poderiam estimular a secreção de paratormônio e, como consequência, o animal desenvolveria um quadro de hiperparatireoidismo secundário renal (Polzin \& Osborne 1995, Brown et al. 1997, Zats 2000).

Os animais dos diferentes grupos estudados não apresentaram alterações na excreção urinária de cada eletrólito, nenhum animal do estudo encontrava-se em estado crítico, apesar dos animais do grupo G3 terem um maior comprometimento da funcionalidade renal em relação aos outros grupos, estes estavam compensados. Um mecanismo complexo que regula a homeostase em pacientes com IRC consegue manter o balanço hidroeletrolítico na maioria deles (Bricker 1982). A capacidade reguladora dos eletrólitos é mantida até os estágios finais de IRC (Polzin et al. 1982). Em estudo, mostrou-se que animais com IRC moderada e compensados são capazes de adaptarem-se a vários tipos de dieta e alterações nos solutos, no entanto, nestes pacientes a capacidade funcional de reserva está perdida e apresentam dificuldade em responder ao estresse fisiológico ou patológico podendo ocorrer crises urêmicas (Boveé 1991) . 
Conforme descrito, o rim tem a capacidade de se adaptar à perda de néfrons, aumentando a taxa de excreção renal exercida pelos néfrons funcionais (Mccaw et al. 1989).

O presente estudo permite concluir que, os mecanismos compensatórios renais observados na doença renal crônica são suficientes para manter a homeostase de $\mathrm{Ca}$, $\mathrm{Na}, \mathrm{P}$ e K pelo menos durante os estágios iniciais. A avaliação da excreção renal de $\mathrm{Ca}, \mathrm{P}, \mathrm{Na}$, e K pode evidenciar déficit da função renal mesmo nos estágios iniciais da doença renal crônica, e pode ser empregada como meio para diagnóstico precoce de insuficiência renal.

Agradecimentos.- À Juliana Toloi, Eugenio, Leticia, Andressa, a todas as pessoas que direta ou indiretamente fizeram parte deste estudo e aos cães que fizeram possível este trabalho.

\section{REFERÊNCIAS}

Barber P.J. \& Elliott J. 1998. Feline chronic renal failure: Calcium homeostasis in 80 cases diagnosed between 1992-1995. J. Small Anim. Pract. 39:111-116.

Barber P.J. \& Elliott J. 1999. Evaluación de la Función Paratireoidea en la Insuficiencia Renal, p.151-160. In: Bainbridge J. \& Elliott J. (Eds), Manual de Nefrologia y Urologia en Pequeños Animales. Romanya/ Valls S.A., Barcelona.

Berliner R.W. \& Giebisch G.J. 1998. Renal tubular secretion of potassium in the normal dog. Milestones in nephrology. J. Am. Soc. Nephrol. 9:1341-1345.

Berndt T.J. \& Knox F.G. 1992. Renal regulation of phosphate excretion, p.2511-2532. In: Seldin D. W. \& Giebisch G. (Eds), The kidney: Physiology and pathophysiology. $2^{\text {nd }}$ ed. Raven Press, New York.

Bienzle D., Jacobs R.M. \& Lumsden J.H. 1993. Relationship of serum total calcium to serum albumin in dogs, cats, horses and cattle. Can. Vet. J. 34:360-364.

Bodey A.R. \& Michell A.R. 1996. Epidemiological study of blood pressure in domestic dogs. J. Small Anim. Pract. 37:116-125.

Boveé K.C. 1991. Influence of dietary protein on renal function in dogs: Diet and renal failure. J. Nutr. 121:128-139.

Bovée K.C. \& Joice B.A. 1979. Clinical evaluation of glomerular function: 24-Hour creatinine clearance. J. Am. Vet. Med. Assoc. 174:488-491.

Bricker N.S. 1982. Sodium homeostasis in chronic renal disease. Kidney International 21:886-897.

Brobst D. 1986. Review of the pathophisiology of alterations in potassium homeostasis. J. Am. Vet. Med. Assoc. 188(9):1019-1025.

Brown S.A., Crowell W.A., Brown C.A., Barsanti J.A. \& Finco D.R. 1997. Pathophysiology and management of progressive renal disease. Vet. J. 154:93-109.

Buranakarl C., Ankanaporn K., Thammacharoen S., Trisiriroj M., Maleeratmongkol T., Thongchai P. \& Panasjaroen S. 2007. relationships between degree of azotaemia and blood pressure, urinary protein:creatinine ratio and fractional excretion of electrolytes in dogs with renal azotaemia. Vet. Res. Commun. 31:245-257.

Chew D.J. \& Nagode L.A. 1990. Renal secondary hyperparthyroidism. Proc. $4^{\text {th }}$ Annual Meeting of the Society of Comparative Endocrinology. American College of Veterinary Internal Medicine, Washington DC., p.17.

Chew D.J. \& Dibartola S.P. 1992. Diagnóstico e fisiopatología da molestia renal, p.1975-2046. In: Ettinger S.J. (Ed.), Tratado de Medicina Interna Veterinaria: moléstias do cão e gato. $3^{\text {rd }}$ ed. Manole, São Paulo.

De Morais H.S.A. \& Chew D.J. 1992. Use and interpretation of serum and urine electrolytes. Seminars Veterinary Medicine and Surgery (Small Animal), p.262-274.

Favus M.J. \& Langman C.B. 1986. Evidence for calcium-dependent control of 1,25-dihydroxyvitamin D3 production by rat kidney proximal tubules. J. Biol. Chem. 261:24.
Finco D.R. 1995. Evaluation of renal functions, p.216-229. In: Osborne C.A. \& Finco D.R. (Eds), Canine and Feline Nephrology and Urology. Williams and Wilkins, Baltimore.

Finco D.R. \& Duncan J.R. 1976. Evaluation of blood urea nitrogen and serum creatinine concentrations as indicators of renal dysfunction: A study of 111 cases and a review of related literature. J. Am. Vet. Med. Assoc. 68:593-601.

Frommer J.P. \& Kurtzman N.A. 1984. Water and electrolyte abnormalities in chronic renal failure, p.405-420. In: Eknoyan G. \& Knochel J.P. (Eds), The systemic consequences of renal failure. Grune and Stratton, Orlando.

Giovaninni L.H. 2003. Avaliação do cálcio sérico e ionizado em gatos sadios e em gatos com insuficiência renal crônica. Dissertação de Mestrado em Medicina Veterinária, Faculdade de Medicina Veterinária e Zootecnia, USP, São Paulo, SP. 84p.

Gleadhill A. \& Mitchell A.R. 1999. Medición Clinica de la función renal, p.137-148. In: Manual de Nefrologia y Urologia en Pequeños Animales. Romanya/Valls S.A., Barcelona

Grauer G.F. 2007. Measurement, interpretation, and implications of proteinuria and albuminuria. Vet. Clin. North Am., Small Anim. Pract. 37:283-295.

Grauer G.F., Thomas C.B. \& Eicker S.W. 1985. Estimation of quantitative proteinuria in the dog, using the urine protein-to-creatinine ratio from a random, voided sample. Am. J. Vet. Res. 46:2116-2119.

Hayslett J.P. 1979. Functional adaptation to reduction in renal mass. Physiologic Rev. 59:137-164.

Knochel J.P. 1992. The Clinical and physiological implications of phosphorus deficiency, p.2533-2562. In: Seldin D.W. \& Giebisch G. (Eds), The kidney: Physiology and pathophysiology. $2^{\text {nd }}$ ed. Raven Press, New York.

Kojika M.M., Lustoza M.D., Notomi M.K., Wirthl V.B.L., Mirandola R.S. \& Hagiwara M.K. 2006. Serum ionized calcium in dogs with chronic renal failure and metabolic acidosis. J. Vet. Clin. Pathol. 35:441-444.

McCaw D.L., Fleming E.J. \& Mikiciuk M.G. 1989. Interpreting the results of urinalysis: A key to diagnosing renal disorders. Vet. Med. 84:281-86.

Newman D.J., Thakkar H. \& Gallacher H. 2000. Progressive renal disease: Does the quality of the proteinuria matter or only the quantity? Clinica Chimica Acta 297:43-54

Polzin D.J. \& Osborne C.A. 1995. Conservative medical management of chronic renal failure, p.508-97. In: Polzin D.J. \& Osborne C.A. (Eds), Canine and Feline Nephrology and Urology. Williams and Wilkins Baltimore.

Polzin D.J., Osborne C.A., Stevens J.B. \& Hayden D.W. 1982. Influence of modified protein diets on electrolyte, acid base, and divalent ion balance in dogs with experimentally induced chronic renal failure. Am. J. Vet. Res. 43:1978-86.

Rosa R.M., Williams M.E. \& Epstein F.H. 1992. Extrarenal potassium metabolism, p.2165-2190. In: Seldin D.W. \& Giebisch G. (Eds), The kidney: Physiology and pathophysiology. $2^{\text {nd }}$ ed. Raven Press, New York.

Rosol T.J. \& Capen C.C. 1996. Pathophysiology of calcium, phosforus and magnesium metabolism in animals. Vet. Clin. North Am., Small Anim. Pract. 26:1155-84.

Rosol T.J., Chew D.J. \& Nagode L.A. \& Capen C.C. 1995. Pathophysiology of calcium metabolism. Vet. Clin. Pathol. 24:49-63.

Rubin S.I. 1997. Chronic renal failure and its management and nephrolithiasis. Vet. Clin. North Am., Small Anim, Pract. 27:1331-1354.

Schenk P.A. \& Chew D.J. 2005. Predicition of serum ionizad calcium concentration by serum total calcium measurement in dogs, Am. J. Vet. Res. 66:1330-1336.

Toto R.D. \& Seldin D.W. 1992. Salt Wastage, p.2144-2156. In: Seldin D.W. \& Giebisch G. (Eds)., The Kidney: Physiology and pathophysiology. $2^{\text {nd }}$ ed. Raven Press, New York.

Zats R. 2000. Insuficiência renal crônica, p.649-659. In: Zats R. (Ed.), Fisiopatologia Renal. Atheneu, São Paulo. 